\title{
Kinetic Modeling of Three Textile Dyes Adsorption from Aqueous Solution onto a Cameroonian Smectite
}

\section{Benessoubo Kada Daniele ${ }^{1}$, Noubissié Eric ${ }^{2}$, Yanne Etienne ${ }^{3}$, Tekoumbo Tedontsa Larissa Canuala ${ }^{1}$, Bike Mbah Jean Baptiste ${ }^{1, *}$}

\author{
${ }^{1}$ National School of Agro-Industrial Sciences, University of Ngaoundere, Ngaoundere, Cameroun \\ ${ }^{2}$ University Institute of Technology, University of Ngaoundere, Ngaoundere, Cameroun \\ ${ }^{3}$ National Polytechnic School, University of Maroua, Maroua, Cameroon
}

Email address:

jbmbahgm@gmail.com (B. M. J. Baptiste)

${ }^{*}$ Corresponding author

\section{To cite this article:}

Benessoubo Kada Daniele, Noubissié Eric, Yanne Etienne, Tekoumbo Tedontsa Larissa Canuala, Bike Mbah Jean Baptiste. Kinetic Modeling of Three Textile Dyes Adsorption from Aqueous Solution onto a Cameroonian Smectite. Journal of Energy, Environmental \& Chemical Engineering. Vol. 6, No. 3, 2021, pp. 71-75. doi: 10.11648/j.jeece.20210603.14

Received: June 30, 2021; Accepted: July 19, 2021; Published: July 27, 2021

\begin{abstract}
In the present study, a Cameroonian smectite was used as an adsorbent to model the adsorption kinetics of three textile dyes (malachite green, methyl red and acid blue 74) from aqueous solution in a batch system. The effects of $\mathrm{pH}$ and temperature were evaluated on the adsorption capacities, the times required to reach adsorption equilibrium and the adsorption mechanisms involved. It can be seen that, although the times required to reach the adsorption equilibrium are independent of the $\mathrm{pH}$ of the medium, the adsorption process studied is favourable in acidic media and is globally independent of temperature. Among the pseudo-first and pseudo-second-order kinetic models used to analyse the experimental data, the pseudo-secondorder model was the best suited to describe the adsorption of the three dyes onto the clay. The mechanism involved, independently of the dye, is therefore a two-step process: the transfer of dye molecules from the solution to the clay surface followed by the interaction between the molecules and the surface. The low value of activation energies indicates that the adsorption of Methyl red, Malachite green and Acid blue 74 on the studied clay is a physisorption process.
\end{abstract}

Keywords: Adsorption, Kinetic Modeling, Textile Dye, Cameroonian Smectite

\section{Introduction}

In their manufacturing processes, many industries like the food industries, the cosmetic industries, screen printing and textiles industries, use dyes to diversify the look of their products. Dyes available commercially for this purpose are varied and diversify, and most of them are difficult to decolorize due to their complex structure and synthetic origin. The discharge of dye wastewater in the environment is aesthetically undesirable and leads inevitably to the degradation of the biological environment $[1,2]$.

Effluents from textile industries are among the most polluting wastewater produces, given the volumes discharged and their composition rich in synthetic dyes [3]. They contain a variety of organic compounds and toxic substances which are harmful to aquatic organisms and can also cause carcinogenic and mutagenic effects $[4,5]$. The color of dye in wastewater reduces the light penetration through the water's surface and, therefore, affects photosynthetic activity in water body. It is therefore evident that the removal of dye from textile effluents is of significant environmental, commercial and technical importance.

Many methods of effluent treatment have been developed, among others: oxidation, microbial degradation, coagulation, membrane filtration and adsorption on solid support [6, 7]. Among all of these methods, adsorption has proven to be the most effective, the least expensive and the easiest to put in place.

Activated carbon is the widely used adsorbent for the removal of colour and treatment of textile effluents but due to its high price it is not used on a great scale [8-10]. That is why material like silica gel and natural clay are being studied 
$[11,12]$. Cameroonian soils are rich in clay [13-15], but their use in the treatment of effluents from textile industries is not well developed.

This study deals with the adsorption abilities of an acidactivated Cameroonian smectite for the removal of three textiles dyes (Methyl red, Malachite green and acid blue 74) from synthetics aqueous solution. The kinetic adsorption data were processed to understand the adsorption mechanism of the three dyes onto the smectite.

\section{Materials and Methods}

\subsection{The Adsorbent}

The clay sample used in this work is a fraction made of particles with sizes lower than $50 \mu \mathrm{m}$ obtained by the wet sieving of a sample of soil aggregate from the locality of
Kousseri in the Far North region of Cameroon. $500 \mathrm{~g}$ of the soil sample is soaked in 1 liter of distilled water for 24 hours. The mixture is subsequently homogenized, placed in an ultrasound water bath for $25 \mathrm{~min}$ to allow a good dispersion of particles in the solution and then filtered using a sieve of $50 \mu \mathrm{m}$ mesh. The filtrate is then dried in an oven at $105^{\circ} \mathrm{C}$ until complete evaporation. The obtained product is then cooled and crushed in an agate mortar and finally conditioned in hermetically closed glass bottles.

\subsection{The Dyes}

Dyes used in this work belong to the three most used groups of dyes in the textile industry (Figure 1). We have malachite green, for triarylcarbeniums group; methyl red for the nitrous group and acid blue 74 for the indigo group. The various chemical formulas of these dyes are as follows.

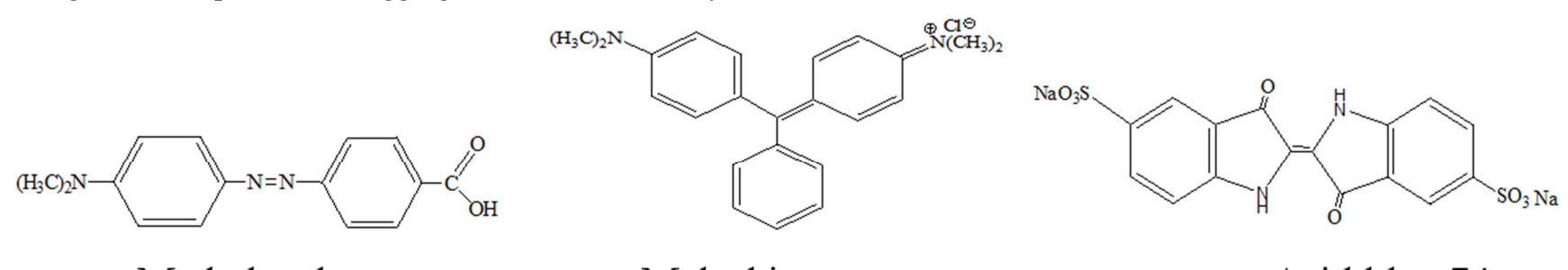

Methyl red

Malachite green

Acid blue 74

Figure 1. The three most used groups of dyes in the textile industry.

\subsection{Kinetic Studies}

Adsorption experiments were performed by bath technique at a solid-liquid ratio of $20 \%$ ( $2 \mathrm{~g}$ of clay in $10 \mathrm{ml}$ of solution). In fact a known volume $\mathrm{V}$ of dye solution having a concentration $\mathrm{C}_{0}$ was introduced in an Erlenmeyer flask (round bottom flask) itself placed in shaken water bath thermostated at a defined temperature. A known mass $\mathrm{m}$ of adsorbent, previously dried overnight at $105^{\circ} \mathrm{C}$, was added to the flask and the mixture was then stirred for the desired time $t$. Thereafter, the contents of the flask were centrifuged at 5000 rpm in a Christ type UJ1 centrifuge for 30 minutes to separate the mixture into its solid and liquid phases. The supernatant is analyzed by UV-spectroscopy and the amount of adsorbed dye is determined by the difference between the initial concentration and the final concentration given by the equation:

$$
q=\frac{\left(C_{0}-C\right)}{m} V
$$

where $C_{0}$ is the initial concentration of the dye solution, $C$ the concentration of the dye solution at the time $t$, and $m$ the mass of clay used.

Kinetics studies were carried out at 23,40 , and $60^{\circ} \mathrm{C}$ for times ranging from $0 \mathrm{~min}$ to $60 \mathrm{~min}$. To study the influence of $\mathrm{pH}$, the adsorption experiments were carried out at $\mathrm{pH}$ of 3 , 7 and 11 . The $\mathrm{pH}$ of the dye solutions were adjusted by the addition of dilute solutions of sulphuric acid $(5 \mathrm{~N})$ or sodium hydroxide $(3 \mathrm{~N})$.

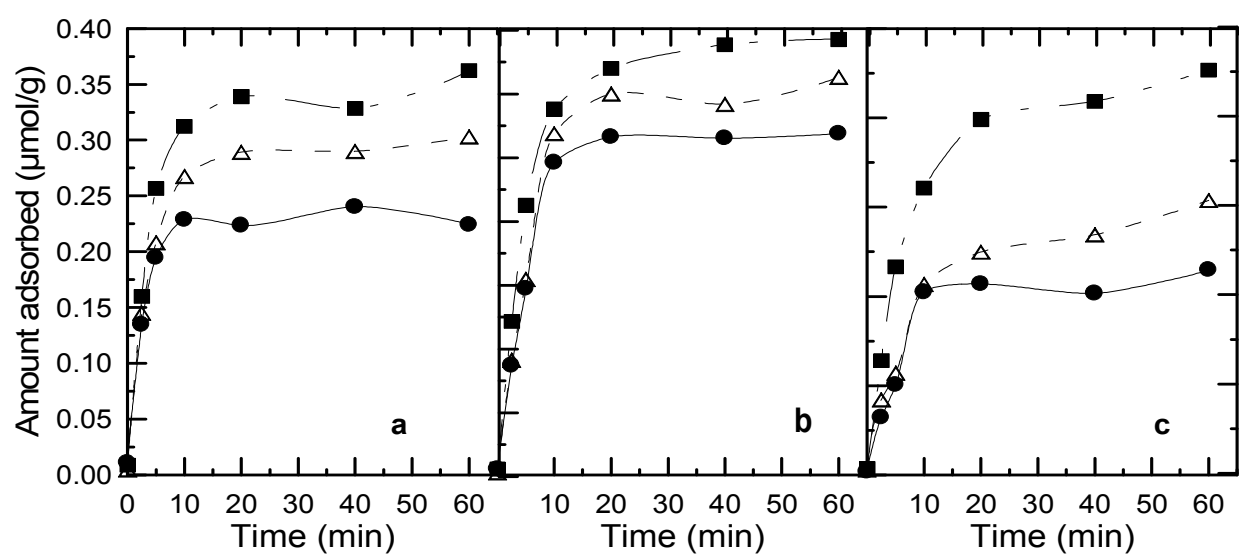

Figure 2. Adsorption kinetics of dyes at $23^{\circ} \mathrm{C}$ and at different $\mathrm{pH}: 3$

$;: 7(\Delta)$; and $11(\bullet) ;(\boldsymbol{a})$ : methyl red; $(\boldsymbol{b})$ : malachite green and $(\boldsymbol{c})$ : acid blue 74. 


\section{Results and Discussion}

\subsection{Influence of PH on the Adsorption of Dyes}

Figure 1 presents the adsorption kinetics of the dyes studied on clay at different $\mathrm{pH}$ at $23^{\circ} \mathrm{C}$.

Figure 2 shows that, in all cases the amount of dye adsorbed per gram of clay increases with time for all $\mathrm{pH}$ values used. The time required to reach adsorption equilibrium is about 20 minutes, showing that the $\mathrm{pH}$ has no great influence on the equilibrium time. It can also be observed that, for each of the dyes the amount adsorbed at equilibrium increase in various manners when the $\mathrm{pH}$ decreases. This increase is very marked in acid blue 74 but less marked for malachite green and methyl red. This is a strong indication that acidic media are favorable for the adsorption of the three dyes studied.

\subsection{Effect of Temperature on Dyes Adsorption}

To evaluate the influence of temperature on dye adsorption, adsorption kinetics were performed at $\mathrm{pH} 3$ and at $23^{\circ} \mathrm{C}$; $40^{\circ} \mathrm{C}$ and $60^{\circ} \mathrm{C}$. Figure 3 shows the results obtained.

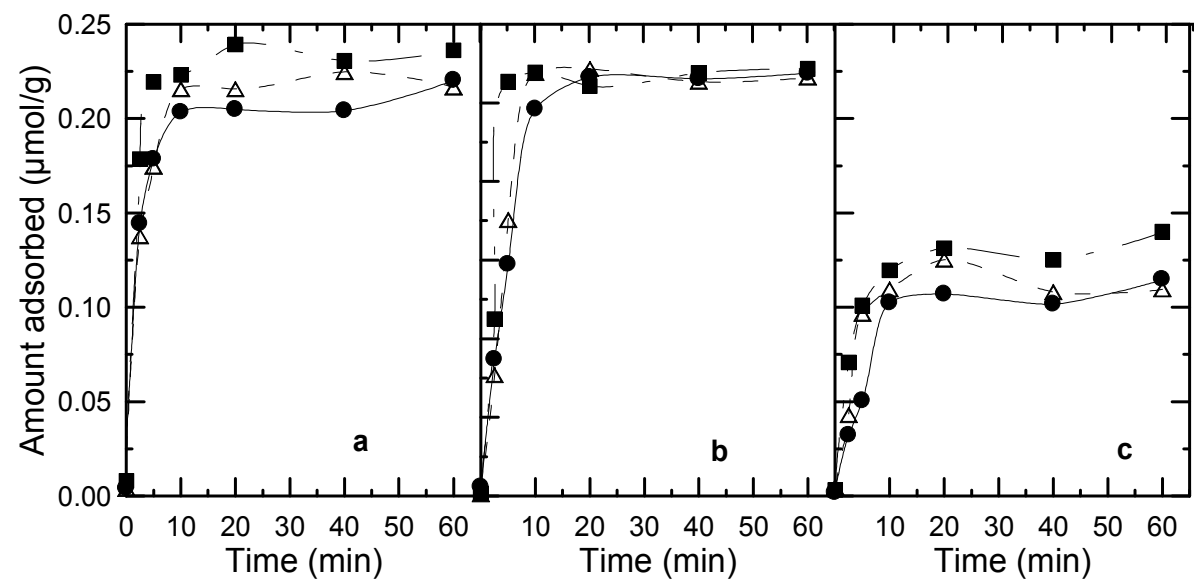

Figure 3. Adsorption kinetics of the dyes at different temperatures; $23^{\circ} \mathrm{C}$ (

$40^{\circ} \mathrm{C}(\triangle)$ et $60^{\circ} \mathrm{C}$

(a): methyl red; (b): malachite green and (c): acid blue 74.

It can be seen from figure 3 that, irrespective of the dye considered and the working temperature, the adsorption process studied reaches equilibrium after 10 minutes of contact time. Moreover, the equilibrium adsorption amounts are almost the same for the same dye, regardless of the working temperature. This result is a strong indication that the temperature has no influence on the adsorption of the three dyes by the smectite used.

However, it can be noted that the amount of acid blue 74 at the adsorption equilibrium are globally half the amount of methyl red and malachite green obtained at equilibrium. This difference is due to the structure of the acid blue 74 molecule. Indeed, the presence of pentacycles in the structure of this molecule reduces its affinity with the clay use.

\subsection{Kinetic Modeling}

In order to have an idea of the mechanism of adsorption of the different dyes on the clay studied, the results of the kinetic study were compared with the pseudo-first order and the pseudo-second order kinetic model according to following equations:

For the pseudo first order kinetic model, the relation $\ln \left(q_{e}-q\right)=f(t)$ was plotted according to the equation $\ln \left(q_{e}-q\right)=-k_{1}+\ln q_{e}$ (where $\mathrm{q}$ is the amount adsorbed after a duration $\mathrm{t}$; qe is the amount at equilibrium and $\mathrm{k} 1$ the pseudo first order rate constant).

For pseudo second order kinetic model, the relation $\frac{t}{q}=f(t)$ was plotted according to the equation $\frac{t}{q}=\frac{1}{k_{2}^{2} q_{e}^{2}}+\frac{1}{q_{e}^{2}}$ (where $\mathrm{q}$ is the amount adsorbed after the time $t ; q_{e}$ the amount adsorbed at the equilibrium and $k_{2}$ the pseudo second order rate constant).

The pseudo-first-order and pseudo-second-order rate constants, the correlation coefficients $\mathrm{R} 2$, and the amounts of dyes adsorbed at equilibrium have been determined and reported in Table 1.

Table 1. The pseudo-second order rate constants at different temperatures and $p H$.

\begin{tabular}{|c|c|c|c|c|c|}
\hline \multirow[b]{2}{*}{ Dye } & \multirow{2}{*}{ Parameters } & \multirow{2}{*}{ Variable } & \multicolumn{3}{|c|}{ Kinetic constants } \\
\hline & & & $k_{2}$ & $q_{e}$ & $R^{2}$ \\
\hline \multirow{6}{*}{ Methyl red } & \multirow{3}{*}{$\mathrm{T}\left({ }^{\circ} \mathrm{C}\right)$} & 23 & 1.020 & 0.467 & 0.991 \\
\hline & & 40 & 1.290 & 0.470 & 0.994 \\
\hline & & 60 & 1.690 & 0.480 & 0.993 \\
\hline & \multirow{3}{*}{$\mathrm{pH}$} & 3 & 0.764 & 0.600 & 0.995 \\
\hline & & 7 & 0.804 & 0.554 & 0.998 \\
\hline & & 11 & 1.020 & 0.467 & 0.997 \\
\hline
\end{tabular}




\begin{tabular}{|c|c|c|c|c|c|}
\hline \multirow{2}{*}{ Dye } & \multirow{2}{*}{ Parameters } & \multirow{2}{*}{ Variable } & \multicolumn{3}{|c|}{ Kinetic constants } \\
\hline & & & $k_{2}$ & $q_{e}$ & $R^{2}$ \\
\hline \multirow{6}{*}{ Malachite green } & \multirow{3}{*}{$\mathrm{T}\left({ }^{\circ} \mathrm{C}\right)$} & 23 & 0.648 & 0.530 & 0.990 \\
\hline & & 40 & 0.731 & 0.520 & 0.992 \\
\hline & & 60 & 1.046 & 0.524 & 0.995 \\
\hline & \multirow{3}{*}{$\mathrm{pH}$} & 3 & 0.654 & 0.590 & 0.997 \\
\hline & & 7 & 0.270 & 0.571 & 0.991 \\
\hline & & 11 & 0.648 & 0.530 & 0.994 \\
\hline \multirow{6}{*}{ Acid blue 74} & \multirow{3}{*}{$\mathrm{T}\left({ }^{\circ} \mathrm{C}\right)$} & 23 & 0.739 & 0.343 & 0.998 \\
\hline & & 40 & 1.274 & 0.334 & 0.997 \\
\hline & & 60 & 1.590 & 0.374 & 0.996 \\
\hline & \multirow{3}{*}{$\mathrm{pH}$} & 3 & 0.510 & 0.486 & 0.992 \\
\hline & & 7 & 0.437 & 0.401 & 0.981 \\
\hline & & 11 & 0.739 & 0.343 & 0.985 \\
\hline
\end{tabular}

It can be seen from table 1 that the correlation coefficients values (R2) obtained for the pseudo-first-order were less than 0.5 . These poor values of $R^{2}$ suggested that adsorption of the three types of dye on the clay is not pseudo-first-order process; The results of the related constants have therefore not been reported in Table 1 .

In contrast to the pseudo-first-order model, the $R^{2}$ values are close to 1 for pseudo-second-order kinetic model, indicating that this model is the most suitable model to take into account in the explanation of the mechanism of adsorption of the studied dyes on clays. In fact, this mechanism is held in two steps and suggests that the dyes diffuse in the first step from the solution to the surface of the adsorbent and in the second step, the fixation of the dyes on the clay.

For the three dyes studied, the quantities of adsorbed dye decrease when the $\mathrm{pH}$ is increased. Thus, indicating that an acidic medium is favorable for their adsorption. The quantities adsorbed for the three dyes up increase with respect to time up to the equilibrium value $q_{e}$. These results are different from those obtained by Flavio et al., [16] in the adsorption of methylene blue by Passiflora edulis fruit residues, whose adsorption is rather favorable in basic medium. They are similar to those of Santhy and Selvapathy [7] and Min-yu and Su-hsia [17], who all used activated carbon to adsorb dyes such as basic violet 4 , basic violet 3 and basic red 9 .

The variations of the adsorbed quantities can be explained in the following way: for malachite green, assuming that the adsorption takes place between the positively charged end of the dye and the negatively charged sites on the clay particles, in a basic medium, the $\mathrm{OH}^{-}$ions neutralize the positive charges of the dye making it less available as shown in figure $4 \mathrm{a}$; in the case of methyl red, the acidic functional group on the contrary, reacts with the clay. In fact, in a basic medium, the acid group of the dye is deprotonated and an equilibrium is established between the acid and its conjugate base which is the most important in the balance (figure $4 \mathrm{~b}$ ).

The decrease in adsorbed amounts in a strongly basic medium may be due to the strong repulsive forces between the negative charges of the deprotonated dye and the negatively charged surface of the clay. It is similar for the acid blue 74 which is deprotonated in a basic medium. One might think that in the case of malachite green there is competition between the $\mathrm{H}^{+}$ions in solution with the positively charged dye but the results show that the affinity for the malachite green dye is stronger. Thus, the forces of attraction between malachite green and the clay surface are stronger than those between the clay surface and $\mathrm{H}^{+}$ions.<smiles>CN(C)c1ccc(C(=C2C=CC(=[N+](C)C)C=C2)c2ccccc2)cc1</smiles><smiles>CCN(C)c1ccc(N=Nc2ccc(C(=O)O)cc2)cc1</smiles>

(b)

Figure 4. Probable reaction equations of the studied dyes in basic medium: (a) malachite green; (b) methyl red.

\subsection{Determination of the Activation Energy}

The determination of the activation energy $\left(E_{a}\right)$ of the adsorption of dyes was done according to the Arrhenius equation: 


$$
k_{2}=A \exp \left[\frac{-E_{a}}{R T}\right]
$$

The pseudo-second-order rate constants were used for this purpose. The Arrhenius equation is commonly expressed in its logarithm form as:

$$
\ln k_{2}=\ln A-\frac{E_{a}}{R} \cdot \frac{1}{T}
$$

where $k_{2}$ is the rate constant and $A$ is the pre-exponential (frequency) factor.

Table 2. Activation energy $\left(E_{a}\right)$ of different dyes adsorption.

\begin{tabular}{llll}
\hline & methyl red & malachite green & Acid blue 74 \\
\hline$E_{a}(\mathrm{~kJ} / \mathrm{mole})$ & $11,9 \pm 0,3$ & $10,6 \pm 0,5$ & $16,9 \pm 0,3$ \\
\hline
\end{tabular}

The range of activation energy indicates the type of adsorption. In fact, activation energies range between 5 and $40 \mathrm{~kJ} \mathrm{~mol}^{-1}$ for a physisorption process, while for a chemisorption process they range between 40-800 $\mathrm{kJ}^{\mathrm{mol}}{ }^{-1}$. The calculated activation energies range from 10.6 to 16.9 $\mathrm{kJ} \mathrm{mol}^{-1}$ for all the dyes studied. These low values of activation energies indicate a physisorption process.

\section{Conclusion}

The kinetics modeling of Methyl red, Malachite green and Acid blue 74 adsorption from synthetic solution by a Cameroonian smectite has been studied. The adsorption process studied is favourable in acidic media and is globally independent of temperature. However, the time required to reach the adsorption equilibrium is independent of the $\mathrm{pH}$ of the medium. The calculated activation energies and the validation of the pseudo-second order kinetic model indicate that the adsorption of Methyl red, Malachite green and Acid blue 74 on the studied clay is a physisorption process which takes place in two stages: the transfer of dyes from the solution to the surface of the clay followed by the interaction between these adsorbates and the surface of the clay. The decrease in adsorbed amounts in a strongly basic medium may be due to the strong repulsive forces between the negative charges of the deprotonated dye and the negatively charged surface of the clay.

\section{References}

[1] Lauren Alberta; Susan M; Sweeney; Karen Wiss, (2005). Diaper dye dermatitis. Official journal of the american academy of pediatric., 116 (3): 2004-2066.

[2] Papic, S; Koprivanac, N; Bozic A. L; Metes, A., (2004). Removal of some reactive dyes from synthetic wastewater by combined Al (III) coagulation/carbon adsorption process. Dyes Pigments., 62: 291-298.

[3] Reid, R., (1996). Go green a sound business decision. J. Soc. Dyers Color. 112: 103-105.
[4] Abadula E., Tzanov T. Costa S., Robra Karl-H., Cavaco-Paulo A and Gübitz G. M. (2000). Decolorization and detoxification of textile dyes with a Laccase from Trametes hirsute. Applied and Environmental Microbiology. Vol 66, $N^{\circ} 8$ p. 3357-3362.

[5] Demirbas E., Kobya M, Sulak M. T. (2008). Adsorption kinetics of a basic dye from aqueous solutions onto apricot stone activated carbon. Bioresource Technology, 99 53685373.

[6] Ciullini I; Tilli S; Scozzafava A, and Briganti F, (2008). Fungal laccase, cellobiose dehydrogenase, and chemical mediators: Combined actions for the decolorization of different classes of textile dyes. Bioresource Technology. 99: 7003-7010.

[7] Santhy K. and Selvapathy P. (2006). Removal of reactive dyes from wastewater by adsorption on coir pith activated carbon. Bioresource Technology, 97, 1329-1336.

[8] Oladimeji T. E, Odunoye B. O, Elehinafe F. B, Oyinlola, Obanla R, Olayemi, Odunlami A., 2021. Production of activated carbon from sawdust and its efficiency in the treatment of sewage water. Heliyon, 7-1, e05960.

[9] Al-Gaashani R, Almasri D, Shomar B., Kochkodan V., 2021. Preparation and properties of novel activated carbon doped with aluminum oxide and silver for water treatment. Journal of Alloys and Compounds 858, 158372.

[10] Zümriye A., 2001. Biosorption of reactive dyes by dried activated sluge: equilibrium and kinetic modeling. Biochemical Engineering Journal. Vol 7, p. 79-84.

[11] Rehman U. M, Manan A, Uzair M, Khan A. S, Ullah A, Ahmad A. S, Wazir A. H, Qazi I, Khan M. A, 2021. Physicochemical characterization of Pakistani clay for adsorption of methylene blue: Kinetic, isotherm and thermodynamic study, Materials Chemistry and Physics, 2691,124722 .

[12] Obijole A. O, Mugera G. W, Mudzielwana R, Ndungu P. G, Samie A, Babatunde A. W, 2021. Hydrothermally treated aluminosilicate clay (HTAC) for remediation of fluoride and pathogens from water: Adsorbent characterization and adsorption modelling. Water Resources and Industry.

[13] Bike Mbah J. B, Benessoubo K. D, Eko M. C, Tekoumbo T. L. C, Elimbi A, Kamga R, (2020). Adsorption mechanisms of pigments and free fatty acids in the discoloration of shea butter and palm oil by an acid-activated Cameroonian smectite. Scientific African 9, e00498.

[14] Nguetnkam J. P., R. Kamga, F. Villiéras, G. E. Ekodeck, and, J. Yvon (2007). Pedogenic formation of smectites in a vertisol developed from granitic rock from Laélé (Cameroon, Central Africa). Clay Miner., 42, 523-537.

[15] Bike Mbah J. B., Kamga R., Nguetnkam J. P., Fanni J. (2005). Adsorption of pigments and free fatty acids from shea butter on activeted Cameroonian clays. Eur. J. Lipid. Sci. Technol. 107, 387-398.

[16] Flavio A. P, Mazzocato A. C; Gushikem Y, (2008). Removal of methylene blue dye from aqueous solutions by adsorption using yellow passion fruit peel as adsorbent. Bioresource Technology., 99: 3162-3165.

[17] Min-Yu Teng et Su-Hsia Lin., (2006). Removal of methyl orange dye from water onto raw and acid activated montmorillonite in fixed beds. Desalination, 201: 71-81. 